Artigo recebido em 20/03/2014

Aprovado em

27/04/2014

SANDRA MOURA

Universidade Federal da Paraíba, Brasil, sandramoura@ccta.ufpb.br

Professora do Programa de Pós-graduação em Jornalismo da

Universidade Federal da Paraíba (UFPB). Doutora em Comunicação e

Semiótica pela Pontifícia

Universidade Católica de São Paulo (PUC-SP).

Pesquisadora do TECJOR

(Grupo de Pesquisa em

Tecnologia e Linguagens Jornalísticas).

\section{EMÍLIA BARRETO}

Universidade Federal da Paraíba, Brasil, emiliabarreto@hotmail. com

Professora na Universidade Federal da Paraíba (UFPB). Mestre em Comunicação e Desenvolvimento Local pela Univesidade François

Rabelais. Pesquisadora do TECJOR (Grupo de Pesquisa em Tecnologia e Linguagens Jornalísticas).

Estudos em Jornalismo e Mídia

Vol. 11 No 1

Janeiro a Junho de 2014 ISSNe 1984-6924

\section{Os critérios de noticiabilidade} no jornalismo de resistência na Paraíba: uma análise dos jornais Edição Extra e O Furo

Sandra Moura e Emília Barreto

\section{Resumo}

1. Ao realizar um mapeamento das características e tendências dos jornais alternativos no Estado da Paraíba, localizado na região Nordeste do Brasil, esta pesquisa tem como objetivo analisar os critérios de noticiabilidade no chamado jornalismo de resistência, que no período da ditadura militar instalada no país atuou como alternativa ao pensamento hegemônico, a voz única da grande imprensa que naquele período ditatorial enveredava cada vez mais no rumo da monopolização da informação e na defesa do sistema vigente. Do ponto de vista aqui defendido, não se pode entender as características específicas do período histórico do regime militar - que no Brasil vigorou de 1964 a 1985 - se não se levar em conta a produção jornalística liderada pela imprensa alternativa. As análises propostas para este artigo são feitas a partir de capas, títulos, entrevista e editorial dos jornais Edição Extra e O Furo.

Palavras-chave: jornalismo e ditadura, jornalismo alternativo, seleção de notícias.

\begin{abstract}
Mapping out the characteristics and tendencies of alternative newspapers in Paraíba State, Northeast Brazil, this research aims at analyzing the criteria of the so called journalism of resistance for passing on the news as they meant to be an alternative to the hegemonic thought at the time of the military dictatorship, the univocal word of the Press that gradually monopolized information and defended the regime. According to our standpoint, one cannot understand the specificities of that historical period - that prevailed between 1964 and 1985 - unless one takes into account the journalistic production carried out by the alternative Press. The analyses proposed for this article are made after collecting covers, titles, interviews and editorials of Edição Extra and O Furo newspapers.
\end{abstract}

Key words: journalism and dictatorship; alternative journalism; selection of news; 


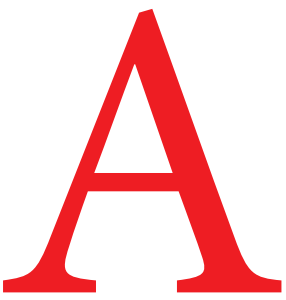

ssim como ocorreu nos demais estados brasileiros durante a ditadura militar, a Paraíba, mesmo com o endurecimento da repressão política, buscou alternativas para oferecer ao leitor de jornal publicações de resistência às formas de autoritarismo do regime vigente e ao jornalismo praticado pelos grandes veículos de comunicação.

Ocorre que essas publicações, no caso de Edição Extra e O Furo, embora com todo seu valor histórico e jornalístico, não tinham, até a presente iniciativa, se tornado objeto de estudo acadêmico. No levantamento bibliográfico realizado, as autoras neste trabalho não localizaram fontes bibliográficas, tais como livros impressos e/ou digitais, monografias, dissertações e teses, que analisassem esses periódicos.

Antes de se passar para as referências e análise propriamente dita dos jornais aqui pesquisados, julgamos pertinente apresentar como vem se construindo o percurso deste trabalho. O surgimento da ideia de se pesquisar esses jornais se deu há quase duas décadas, mais especificamente quando uma das autoras, ao ministrar para estudantes de Jornalismo a disciplina "Imprensa Alternativa" no curso de Comunicação da Universidade Federal da Paraíba, se deparou com a ausência de bibliografia sobre jornais alternativos paraibanos.Existiam, na ocasião, estudos e pesquisas publicados em livro de jornais alternativos brasileiros, mas que não incluíam a Paraíba como um estado onde também jornalistas tinham criado, ainda no período da ditadura militar, publicações alternativas ao chamado jornalismo da grande imprensa.
As publicações bibliográficas acessíveis à disciplina "Imprensa alternativa", naquele momento, giravam em torno das produções jornalísticas alternativas já conhecidas, como O Pasquim, Opinião, Movimento, Bondinho, periódicos esses que se concentraram na região Sudeste do país, principalmente no Rio de Janeiro e São Paulo.

A partir daí, vieram os questionamentos da professora e alunos na disciplina sobre a repercussão na Paraíba da imprensa alternativa na época da ditadura militar. As perguntas iniciais eram: "Assim como houve na política, nas artes, nas universidades paraibanas, formas de resistência ao sistema ditatorial, o jornalismo teria também combatido esse regime?", "Quais foram as alternativas apresentadas pelos jornalistas paraibanos à chamada grande imprensa?", "Quais as publicações e quem delas participou?".

O passo inicial foi localizar os participantes desses jornais e tentar obter informações sobre a imprensa alternativa nesse período, além de ter acesso às edições desses periódicos. Promoveram-se, então, na disciplina debates e entrevistas com três desses profissionais, dois deles atuaram no jornal $O$ Furo e um no jornal Edição Extra. Com eles, veio a memória desses jornais, contada pelas lembranças que esses jornalistas mantinham do período em que ainda muito jovens protagonizaram as transformações que propunham e a busca por espaços alternativos à grande imprensa.

No entanto, não foi dessa vez que tivemos acesso às edições desses jornais. Nenhum dos entrevistados guardava em seus arquivos, pelo menos até aquele momento, exemplares dessas publicações como registro desse período. 
Concluída a disciplina e diante das dificuldades encontradas para o resgate dessa história da imprensa alternativa na Paraíba, chegou-se a elaborar um projeto de pesquisa sobre o assunto, mas que não foi posto em execução.

Passadas quase duas décadas do surgimento da ideia de investigar a imprensa alternativa na Paraíba, e neste ano de 2014 em que no Brasil se registram os 50 anos do Golpe Militar, retomamos o interesse pela presente pesquisa. Dessa vez, duas docentes pesquisadoras uniram

\section{As mudanças do regime militar} não se limitaram à economia e política. Alterou o modo que uma parcela de jornalistas

\section{tratou a informação jornalística}

os seus interesses acadêmicos para a elaboração de um projeto que investigasse a origem desses jornais, sua forma de organização, seu método de apuração e levantamento das informações, suas características, seus modos de construção dos gêneros jornalísticos e seus critérios de noticiabilidade.

Para isso, já não mais seriam suficientes apenas os depoimentos dos ex-editores, repórteres, colunistas e responsáveis pela criação dos jornais, mas se tornou fundamental o acesso às edições dos jornais.
Nessa fase, a busca se volta para a localização de pesquisas - concluídas ou em andamento - sobre os jornais Edição Extra e O Furo. Foram várias tentativas em páginas na internet, consulta a arquivos da Biblioteca da Universidade Federal da Paraíba, sem êxito. Quase duas décadas depois da primeira consulta sobre essa temática observamos que continuava a lacuna nos estudos sobre esses periódicos. Apenas localizamos uma reportagem sobre o assunto, com características informativas.

As pesquisadoras passaram a procurar edições desses periódicos em acervos nas universidades e particulares, sem sucesso. Paralelamente, efetuaram contatos com jornalistas, chargistas e publicitários que fizeram parte desses jornais, formando uma rede que além destes incluía outros profissionais da área de comunicação, amigos, amigos dos amigos. Informações desencontradas levavam a inclusão de cada vez mais pessoas com um sucesso inversamente proporcional. Algumas pistas de quem teria o material foram surgindo, a quase totalidade sem fundamento. Foram quase dois meses de busca intensa até a descoberta de que dois dos profissionais que trabalharam nesses jornais tinham os periódicos. Outro esforço foi chegar até eles que disponibilizaram o acervo pessoal para o presente estudo. As pesquisadoras se surpreenderam com a ausência de preservação desta memória e a consequente dificuldade de acesso aos exemplares analisados.

\section{Histórico dos jornais Edição Extra e O Furo:}

Os jornais nos foram entregues para estudo de duas formas. Edição Extra com 
suas edições encadernadas. O Furo com suas edições soltas, sem encadernação. O jornal Edição Extra se apresenta em formato tablóide, off-set, em 12 edições impressas, com 20 páginas cada uma, com fotos, charges e anúncios publicitários, com periodicidade semanal. $\mathrm{O}$ primeiro número traz em seu expediente uma equipe formada por Valdez Juval da Silva (Diretor presidente), Henriette Maria Lemos da Silva (Diretora gerente), Luiz Andrade (Redator chefe), Alarico Correia (Secretário), Anco Márcio (Editor de Humor), Gilvan de Brito (Editor Político), Júlio Vieira (Editor da Cidade), Luzardo Alves (Editor de Arte), Atelier Esquema (Diagramação).

Edição Extra tem como slogan "Um jornal diferente”. O primeiro número saiu sem data da edição. O segundo número vem datado de 9 a 16 de agosto de 1971. E o último número, referente à edição 11 , é datado de 11 a 17 de outubro de 1971.

O jornal O Furo é composto por cinco edições, em formato tablóide, off-set, com 24 páginas, com periodicidade quinzenal. O primeiro número é datado de 16 a 31 de dezembro de 1979. O último número refere-se apenas ao mês março e ano de 1980. O expediente do jornal na sua edição de estreia apresenta em seus quadros Alberto Arcela e Marcos Pires (Diretores-responsáveis); Richard $\mathrm{Mu}$ niz (Editor responsável), Marcos Nicolau (Secretário de Redação e Arte), Walter Galvão, Alberto Arcela, Nonato Guedes, Maria Naélia, Marcos Tavares, Anco Márcio, Marta Kristine, Antonio Augusto Arroxelas, João Manoel de Carvalho, Bruno Steinbach, Hilton Lima, Luzardo, Antônio Barreto Neto (Colaboradores).

Ao catalogar as publicações da imprensa alternativa, o Centro de Imprensa Al- ternativa e Cultura Popular do RIOARTE, conceitua essas produções como alternativas com base nas seguintes classificações:

Os periódicos que contestavam diretamente o regime de exceção imposto a partir de 1964 e os que constituíam veículos de movimentos e correntes de esquerda; os que não possuíam meios de comunicação de massa, que pensavam de forma independente, que não estavam ligados a esquemas governamentais ou econômicos e que não aceitavam o autoritarismo dominante não só na política, mas nos costumes, no comportamento, na linguagem, nos valores, propondo novos conteúdos e uma diagramação arrojada para época. (CATÁLOGO DA IMPRENSA ALTERNATIVA, 2014).

Das classificações propostas, diríamos que a segunda predomina nos jornais Edição Extra e O Furo, ou seja, tratam-se de periódicos que não estavam ligados a meios de comunicação de massa, que atuavam de forma independente, que não aceitavam o autoritarismo dominante não só na política, mas nos costumes, no comportamento, na linguagem, nos valores, propondo novos conteúdos e uma diagramação criativa para o cenário jornalístico na época.

Assim, o período histórico inaugurado no Brasil pelo regime militar não produziu somente mudanças econômicas e políticas, mas também uma mudança no modo pelo qual uma parcela de jornalistas tratou a informação jornalística. Das publicações nacionais alternativas da época, O Pasquim é o jornal que influenciou os jornais Edição Extra e O Furo, na forma de abordar os fatos, com uma linguagem coloquial, aproximando-se da conversa informal e impregnada pelo humor.

Após as referências históricas sobre os jornais pesquisados, como origem e 
composição da equipe, passaremos às análises dos critérios de noticiabilidade empregados pelos dois periódicos, a partir de capas, títulos e dos gêneros notícia e editorial. Cabe ressaltar que as observações e comentários aqui são próprios de uma pesquisa que se inicia, lembrando que este trabalho ainda terá um grande percurso pela frente.

\section{Análise dos jornais Edição}

\section{Extra e O Furo}

No período da ditadura militar, os braços da censura alcançavam as expressões artísticas, culturais e, de modo contundente, o jornalismo. Em tempos de empresas jornalísticas amordaçadas, os jornais da chamada imprensa alternativa constituíam o espaço privilegiado de resistência. Então, como eram estabelecidos os critérios de noticiabilidade a partir desta lógica de resistência e de censura que originou estes jornais? O que deveria ser dito? Ou melhor, o que queriam dizer, transformar em notícia?

Buscando compreender as questões formuladas recorremos a Traquina, quando diz que o conceito de noticiabilidade compreende:

O conjunto de critérios e operações que fornecem a aptidão de merecer um tratamento jornalístico, isto é, possuir valor como notícia. Assim, os critérios de noticiabilidade são o conjunto de valores-notícia que determinam se um acontecimento, ou assunto, é suscetível de se tornar notícia, isto é, de ser julgado como merecedor de ser transformado em matéria noticiável e, por isso, possuindo 'valor notícia' (TRAQUINA, 2005, p. 63).

Recorremos, igualmente, a Marcondes Filho quando afirma que torna-se notícia o que é "anormal", mas cuja anormalidade interessa aos jornais como porta-vozes de correntes políticas. (...) O jornal, assim, arranja, acomoda o extraordinário na sua argumentação diária contra setores ou grupos sociais. $\mathrm{O}$ extraordinário, na imprensa "séria", só vira notícia quando pode ser utilizado como arma no combate ideológico (MARCONDES FILHO, 1989, p. 13).

No caso dos jornais analisados percebemos que a sensibilidade jornalística para a seleção da notícia não se guiava por uma percepção de noticiabilidade meramente técnica mas, sobretudo, naquela de cunho político. Interessava mostrar a contra-notícia, ou seja, o que a mídia tradicional não mostrava, o que ia no sentido contrário, o que não era do seu interesse, tão pouco da ditadura, e se afirmar como território de oposição política, de mudanças culturais e de experimentação de uma linguagem jornalística inovadora.

Num contexto de cerceamento à liberdade de expressão, os jornais analisados se propunham não a noticiar o fato tal como aparecia na grande imprensa, mas em possibilitar outras versões deste. A burla da censura era o grande desafio. Eles exerciam o papel do mediador que busca revelar o que era apagado, proibido. A estratégia usada por estes jornais alternativos para "indução do leitor" (FAUSTO NETO, 2013) consistia na capacidade maior ou menor de despistar as antenas da censura usando artifícios de linguagem como ironia, duplo sentido, metáforas, humor, recursos imagéticos, além de amplificar a fala de quem não tinha espaço na grande imprensa. Entrevistas com figuras emblemáticas da 
esquerda como o arcebispo da Paraíba D. José Maria Pires, o ex-governador de Pernambuco Miguel Arraes, o líder camponês Gregório Bezerra e o arcebispo de Recife e Olinda D. Helder Câmara, são exemplos significativos (figuras 1 e 2).

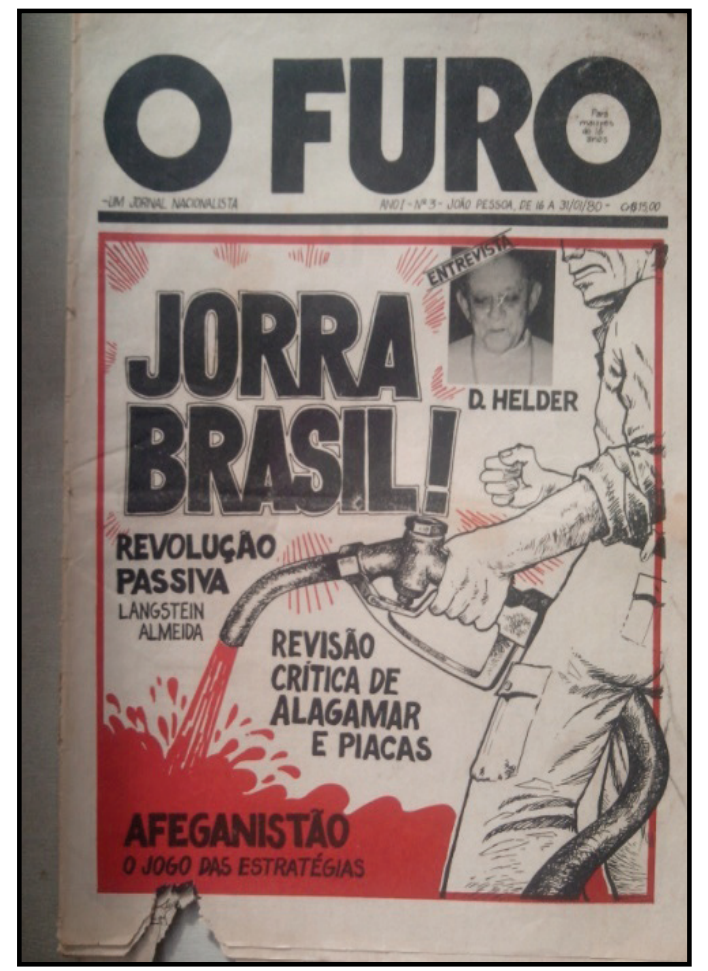

Figura 2: Imagem da edição no. 3

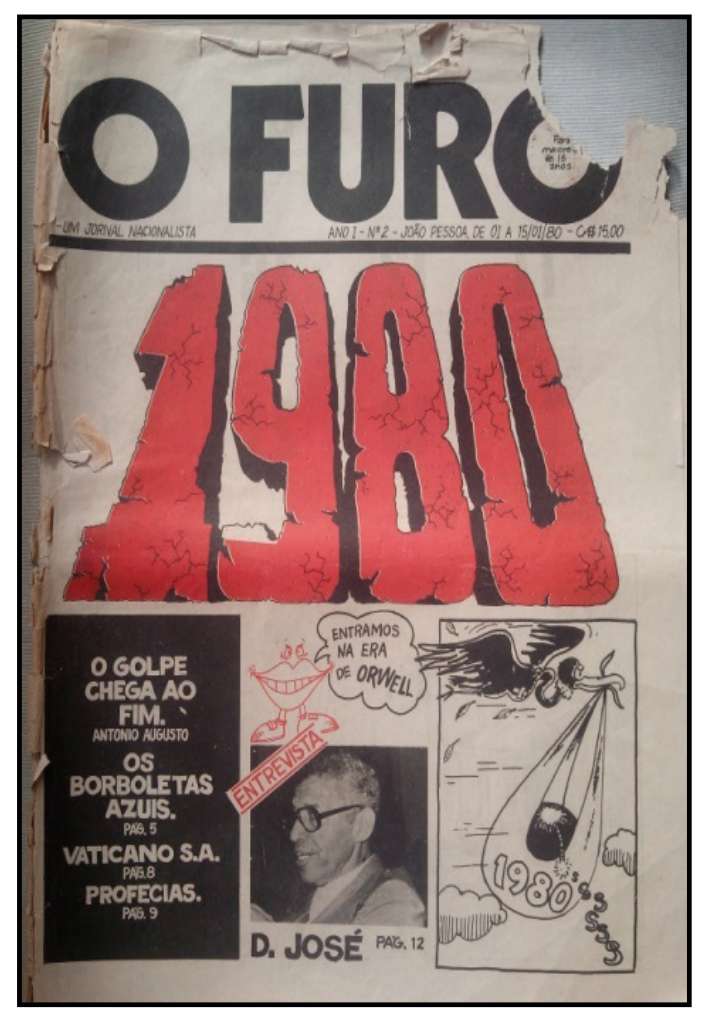

Figura 1: Imagem da edição no. 2

\section{Capas, chamadas e títulos: enquadrandooacontecimento}

Os elementos gráficos (textuais e imagéticos) são utilizados como atrativos ao leitor na capa dos jornais. Em $O$ Furo e Edição Extra não era diferente. Ambos, cada um ao seu modo e no seu contexto, lançaram mão destes elementos para criar suas identidades visuais $\mathrm{e}$ discursivas. Mostravam-se como espaço de fala desvinculada da lógica capitalista e da ideologia dominante, como espaço alternativo ao pensamento hegemônico da ditadura e como estratégia para driblar a censura vigente. $\mathrm{O}$ nome do jornal Edição Extra sugere a existência deste fato extraordinário, merecedor de ser noticiado com uma tiragem extra do jornal. O mesmo apelo encontramos no título do jornal $O$ Furo, expressão que designa a notícia trazida ao leitor em primeira mão, em exclusividade. $\mathrm{O}$ caráter de noticiabilidade da capa nos dois jornais oscilava entre uma linha mais crítica e politizada, no caso de O Furo e outra mesclada com apelos de erotização com o uso predominante da figura de mulher associada a frases de duplo sentido contendo insinuações como no caso de Edição Extra, com as seguintes chamadas: "Este jornal é amigo do peito" (figura 3), "Bom mesmo vai ser no quarto" (figura 4), "No quarto com Márcia de Windsor" (figura 5) e "Boa mesmo é a entrevista com o computador na página 4" (figura 6). Este fato pode denotar certo viés machista, como um recurso para a captura deste leitor, mas pode ser interpretado, também, como uma camuflagem que não permitisse revelar de forma completa o conteúdo político subjacente, um artifício para driblar a censura. 


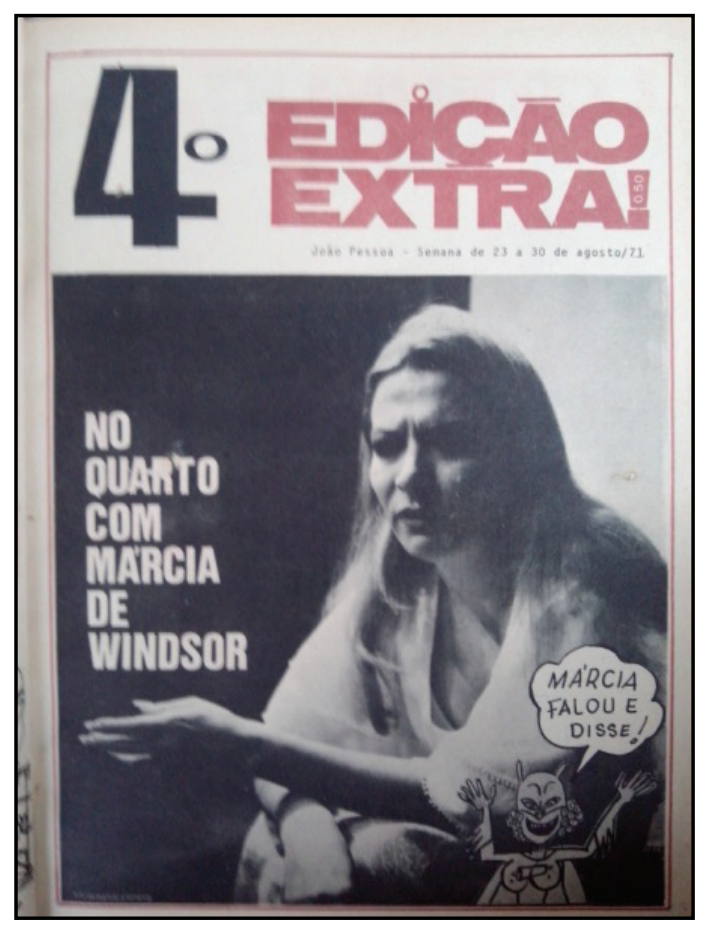

Figura 5: Imagem da edição no. 4

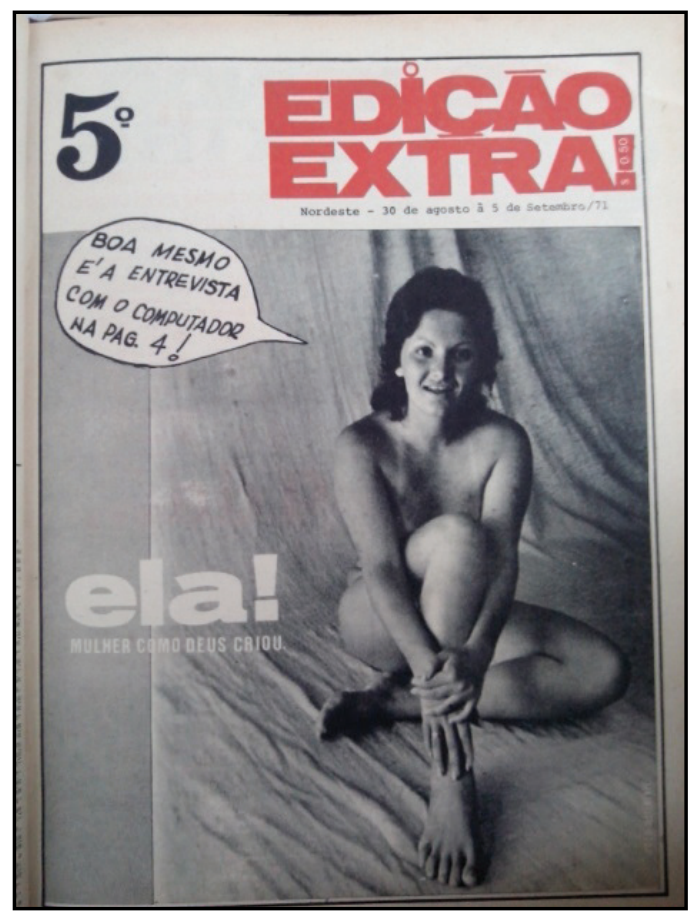

Figura 6: Imagem da edição no. 5

Por analogia, podemos comparar as capas dos jornais às embalagens dos produtos que a um só tempo seduzem, informam e protegem os seus conteúdos, construindo os sentidos que lhe interessaram para captura do público consumidor. Deste modo, as capas buscam sintetizar o espírito de cada um desses jornais, seus principais conteúdos, os pontos de ancoragem sobre os quais se assentava um presumível contrato de leitura (VERÓN, 2004) que objetivava capturar e manter o leitor lançando mão de uma estética que contrariava os padrões vigentes, à época, da chamada grande imprensa. Esta irreverência ou transgressão na forma de construir as capas criou um estilo híbrido que se aproximava mais das capas de revistas do que de jornais. Esta nova linguagem foi introduzida por jornais alternativos como O Pasquim, Coojornal, Opinião, entre outros.

Os títulos são considerados por Medina (1978, p.118-119) como um dos apelos verbais trabalhados de maneira consciente na mensagem jornalística para "chamar a atenção e conquistar o leitor para o produto". Segundo a autora, os apelos da mensagem conquistaram um estilo próprio que os equipara à "embalagem no produto publicitário". Entendemos que na capa dos jornais este caráter sedutor atribuído ao título se revela ainda mais contundente e que a concepção das capas se forja na junção, no diálogo, entre a parte textual das chamadas e o apelo visual que lhes é transferido pela intervenção do design gráfico, incluindo obviamente, as ilustrações.

Nas capas do jornal Edição Extra e $O$ Furo, os títulos anunciavam as notícias, enquadravam a perspectiva editorial, resumiam o espírito de cada jornal. No Edição Extra as capas são econômicas com poucos elementos verbais $\mathrm{e}$ imagéticos. A imagem de uma mulher que começa discreta (figura 3) e aos poucos vai dominando a cena (figuras $4 \mathrm{e}$ 6). Os títulos são "apagados" visualmente, como que a despistar o conteúdo político ao qual estavam associados (figuras 3 e 6). É importante dizer que o Edição Extra 
foi lançado em 1971 e, portanto, teve sua breve vida durante os anos duros de ditadura, enquanto que $O$ Furo apareceu em 1979, quando a força da ditadura já esmaecia e iniciava-se o processo de abertura política.

As capas de $O$ Furo constituem um ambiente visual mais atraente, lúdico, por vezes se aproximando de uma charge com desenhos que mesclam humor e crítica. As chamadas de suas capas se constituíam em uma "mensagem-consumo", como diria Medina (1978, p. 119) a demandar "título de apelo forte, bem nutrido de emoções, surpresas lúdicas, jogos visuais, artifícios lingüísticos", podendo ser equiparado a um anúncio publicitário.

O Furo soube utilizar a mescla destes elementos para construir capas dinâmicas, atraentes e que sintetizavam a linha crítica do jornal. Exemplo do que dissemos é visível na figura 7 , onde temos uma ilustração do nome do jornal aparecendo como uma pichação de muro, numa alusão ao que acontecia na realidade, quando os muros foram pichados pelos militantes de esquerda com mensagens de resistência e "subversão" ao regime ditatorial.

1- Segundo o jornal, agentes do governo infiltrados na igreja estariam incitando lideranças camponesas do município de Alhandra a se voltarem contra a instituição, numa campanha da direita para "desmoralizar" a CDDH. Wanderley Caixe, paulista, foi convidado por D. José Maria Pires para dirigir o Centro. $D$. José Maria Pires na ocasião era o arcebispo de João Pessoa e reconhecido por sua
Outro exemplo relevante está na figura 8 onde vemos vários homens fazendo uma força colossal para "puxar o saco" de um gigante deitado, numa alusão aos inimigos do povo que adotavam posição de subalternidade em relação à ditadura, em detrimento do interesse coletivo.

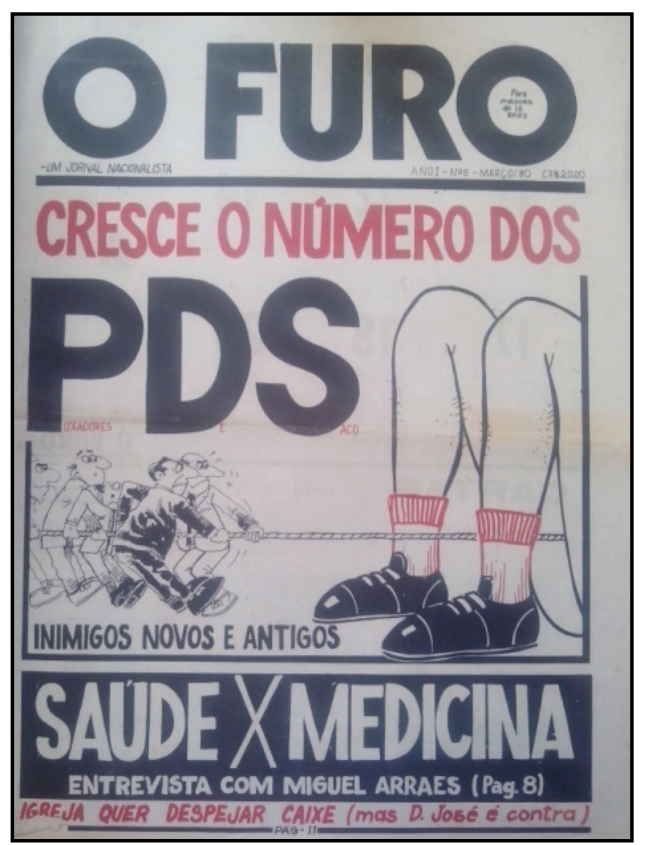

Figura 8: Imagem da edição no.5

As capas de O Furo explicitavam com clareza os propósitos editoriais do jornal. Ficava clara a posição contrária ao regime militar, mesmo nas chamadas de capa sem a relevância das anteriores, mas que traziam à tona temas polêmicos como aborto ilegal, prostituição (figura 9), ocupação de terras e as manobras dos latifundiários para interferir no movimento social das Ligas Camponesas pela interferência na direção do Centro de Defesa dos Direitos Humanos (figura 8) ${ }^{1}$.

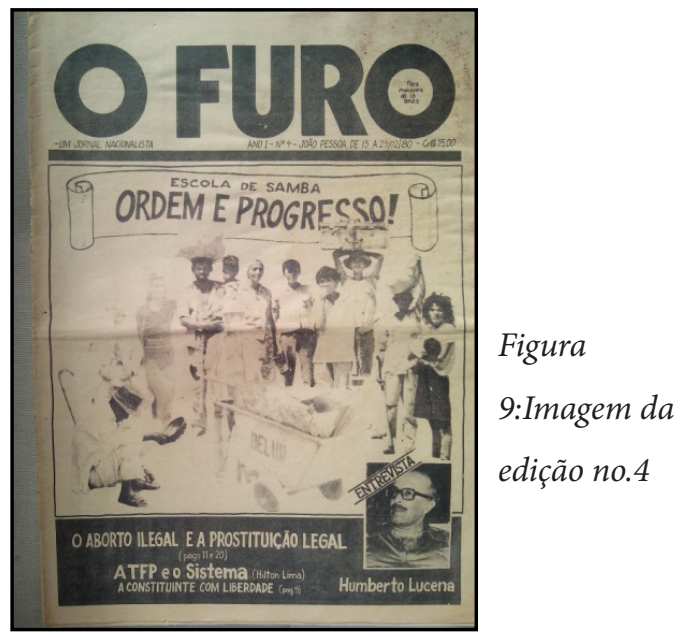




\section{Os editoriais}

É de se notar que a linguagem coloquial, aproximando-se de uma conversa informal, é utilizada nos editoriais dos dois jornais. No caso de Edição Extra, o coloquialismo da linguagem surge em expressões como: “Tá bom”, "E tamo aqui pra isso mesmo", "não tá nem doida", "tamos mais para.... O jornal chega a empregar também cacoetes verbais, como no trecho abaixo: "A gente percebe que os distintos estão falando em termos ecológicos urbanos, né?”.

Outro aspecto a se observar nos editoriais do jornal Edição Extra é o uso da metalinguagem, isto é, o periódico fala de si mesmo, faz uma leitura relacional, onde as referências apontam para si próprias. Como podemos notar no editorial no. 1, intitulado "Falei", em que o jornal informa qual o seu público, ou seja, para quem se dirige:

Para usar de sinceridade, não pretendemos inovar muita coisa, não. Temos a intenção, isto sim, de contribuir para ajudar as pessoas a participarem mais da atividade vivencial em comum, tomando conhecimento das coisas que acontecem em nosso redor que apresentadas no conjunto das informações padronizadas, passam mais das vezes, desapercebidas ou não são assimiladas inteiramente. Imaginamos um jornal para consumo geral, num estilo ameno e enxuto, dosado de algum humor, sem deformar a informação, evidentemente (Edição Extra, 1971, no. 1, p.3).

Nesse mesmo editorial, é utilizado o recurso metalingüístico para informar que não há um engajamento políticopartidário do jornal, como podemos verificar nesse parágrafo:
Evitaremos como a peste, as posições unilaterais, as opiniões partidárias, a vinculação com esquemas, grupos ou pessoas para aceitar de bom grado o compromisso de editar um semanário descontraído no modo de colocar as questões, de ver e comentar as coisas mil. (Edição Extra, 1971, no. 1, p.3).

Mas é no trecho seguinte que o editorial revela que os critérios de seleção da informação não passam pelos recursos sensacionalistas. O jornal buscava separar as informações relevantes daquelas que tinham apenas o objetivo de comover o público leitor. E utiliza-se da metáfora "Mais para colibri do que para urubu" para explicar a sua linha editorial:

Correremos as léguas para evitar os assuntos trágicos, sensacionalistas, lixo branco da sociedade, produto de fácil aceitação e bastante rentável. Garantimos estar mais para colibri do que para urubu (Edição Extra, 1971, no. 1, p.3).

O editorial do jornal O Furo, em sua edição no. 5, enfatiza a existência de problemas sociais. E adota, perante essas questões sociais, uma postura crítica que se apresenta logo no início no título "Para onde vais?" e "Sair para onde?". Dessa forma, o periódico anuncia para quem dirige a sua indagação:

A pergunta vale para ti, misero nordestino que se deixa enganar pela maquiavélica máquina da cidade grande que a tudo e a todos devora, sem piedade. Que deixa as terras do sertão e do brejo pra morrer ao despencar dos andaimes e dormir em favelas, entre as balas enganosas da polícia. E por que não ficas aqui mesmo? (O Furo, 1980, no. 5, p. 3).

No parágrafo seguinte, o editorial esclarece o objetivo da pergunta: 
Pois a pergunta é assim como uma introdução para um hino rebelde de estímulo à luta pacífica para a fixação do homem nordestino à terra, que ele aprendeu a amar e desejar como uma mãe deseja o filho, seja ele assassino, traidor ou seu próprio algoz (O Furo, 1980, no. 5, p. 3).

O editorial refere-se diretamente ao processo migratório gerado nos períodos de seca pela falta de chuva na região Nordeste e que força a migração de famílias nordestinas. Esse êxodo historicamente tem levado trabalhadores dessa região a tentarem a sobrevivência em outros estados do país, em especial em São Paulo. As condições em que são transportados esses nordestinos - geralmente saem de sua terra natal em caminhão de pau de arara - geram preconceito e discriminação, como se verifica na crítica manifestada pelo editorial:

Principalmente por que esse rótulo infame de "pau de arara" já pesa muito na cabeça de todos, e o comodismo nunca foi bom pra ninguém, nem mesmo para os opressores que usam de garra e força de vontade para explorar melhor e enriquecer ainda mais (O Furo, 1980, no. 5, p. $3)$.

O editorialista conduz a sua argumentação no sentido de estimular o nordestino a se fixar na sua terra natal e, de imediato, desistir de migrar para região Sudeste, no caso para a cidade de São Paulo. Para isso, usa como recurso argumentativo o preconceito e a exploração da mão de obra dos trabalhadores vindos da região Nordeste do Brasil. Como se pode verificar no trecho seguinte:

Para o inferno que queima a resistência da maior força produtiva desse país? Para uma São Paulo que insiste em não te ver como pessoa humana, digna do mesmo amor transferido para os entes queridos, da mesma compaixão para os parentes e amigos que morrem subitamente e não passam pela lenta agonia que conduz a morte, os teus? (O Furo, 1980, no. 5, p. 3).

A crítica do editorial se reveste de tom persuasivo e insiste na permanência do nordestino na sua região. E se utiliza de elementos próximos do universo do nordestino para tentar convencê-lo a se fixar na terra natal.

Não, não deves sair. Nem agora, nem nunca mais. Muito embora desconheças o que te espera do outro lado da cerca, pois tua ilusão avassaladora como que ofusca a visão da melhor solução que está tão próxima que chega a se confundir com os pássaros e mandacarus que te cercam (O Furo, 1980, no. 5, p. 3).

\section{Considerações}

Nesses momentos iniciais da pesquisa, já podemos vislumbrar a contribuição que esses jornais Edição Extra e O Furo propuseram para o jornalismo paraibano, com transformações inspiradas em periódicos como $O$ Pasquim quanto à linguagem, à sua forma de estruturação dos gêneros jornalísticos.

Como é o caso da notícia em que a sua construção se dá a partir de elementos discursivos que não interessavam ao regime ditatorial vigente $e$, consequentemente, não eram também de interesse da chamada grande imprensa.

Personagens como o líder camponês Gregório Bezerra, o arcebispo D. José Maria Pires, que foram trazidos para as páginas de destaque dos jornais Edição Extra e O Furo, como as de entrevista, não 
eram consideradas fontes jornalísticas "confiáveis" para a chamada grande imprensa.

Nesse sentido, um enfoque crítico da realidade sócio-político cultural dos anos de autoritarismo passa inevitavelmente pelo estudo também dessas produções jornalísticas surgidas na Paraíba.

Cabe ressaltar que a adoção de uma linguagem impregnada de humor, de coloquialismo, de críticas, de metáforas, de metalinguagem, já nos possibilita, nessa fase embrionária da nossa pesquisa, empreender que esses jornais buscavam as transformações não apenas no sistema autoritário vigente, mas também na própria forma de escrever notícias, editoriais e elaborar entrevistas.

Nesse processo, o motivo da escolha já se configura um critério de noticiabilidade. A seleção recai sob aqueles personagens e temas que foram silenciados, ocultados, excluídos das páginas dos jornais da chamada grande imprensa. Como verificamos na análise dos jornais e no depoimento de um dos responsáveis pelo jornal $O$ Furo. Alberto Arcela (apud ALMEIDA, 2014), mencionou a entrevista de Dom Hélder Câmara, então arcebispo de Olinda e Recife, como um fato marcante e emotivo para a equipe do jornal. O religioso estava fora dos meios de comunicação tradicionais por pressão do regime militar. A entrevista foi concedida no Seminário do Miramar, em João Pessoa, durante encontro de bispos brasileiros.

\section{Referências Bibliográficas}

ALMEIDA, Marina. A voz alternativa na imprensa paraibana: a breve história de um jornal alternativo. Disponível em: $<\underline{\text { http://www.insite.pro.br/2010/Mar\%C3\%A7o/Reportagem\%20 }}$ O\%20Furo\%20Marina\%20Almeida.pdf $>$ Acesso em: 20 de jan. 2014.

EDIÇÃO EXTRA. João Pessoa, Ano I, no. 1, s/d. . João Pessoa, 16 a 23 ago. 1971, ano I, no. 3. . João Pessoa, 23 a 30 ago. 1971, ano I, no. 4. João Pessoa, 30 de ago. a 5 set. 1971, ano I, no. 5.

FAUSTO NETO, Antônio; SGORLA, Fabiane. Zona em construção: acesso e mobilidade da recepção na ambiência jornalística. Anais Compós 2013. Disponível em: $<\underline{\text { http:// }}$ compos.org.br/data/biblioteca 2110.pdf> Acesso em: 28 jan. 2014.

CATÁLOGO DA IMPRENSA ALTERNATIVA. Disponível em: <http://www.rio.ri.gov.br/ dlstatic/10112/4203404/4101358/catalogo imprensa alternativa.pdf> Acesso em: 19 de fev. 2014.

KUCINSKI, Bernardo. Jornalistas e revolucionários. São Paulo: Edusp, 2003.

MEDINA, Cremilda. Notícia, um produto à venda. São Paulo: Summus, 1988.

MARCONDES FILHO, Ciro. O capital da notícia. São Paulo: Ática, 1989. 
O FURO. João Pessoa, 16 a 31 dez. 1971, ano I, no. 1.

_. João Pessoa, 01 a 15 jan. 1980, ano I, no. 2. . João Pessoa, 16 a 31 jan. 1980, ano I, n. 3 . João Pessoa, 15 a 29 fev. 1980, ano I, no. 4 . João Pessoa, mar. 1980, ano I, no. 5.

TRAQUINA, Nelson. Teorias do Jornalismo. Florianópolis: Insular, Ed. 2, 2005. VERÓN, Eliseo. Fragmentos de um tecido. São Leopoldo: Unisinos, 2004. VILELA, Gileide et all. Os baianos que rugem. Salvador: Edufba, 1996.

Este artigo e todo o conteúdo da Estudos em Jornalismo e Mídia estão disponíveis em https://periodicos.ufsc.br/index.php/jornalismo

Estudos em Jornalismo e Mídia está sob a Licença Creative Commons 2.5 